\title{
“BONNIE E CLYDE”: UMA ANÁLISE EM DOIS TEMPOS (1967-2013)
}

\section{Thaís Lisboa Roussille Bandeira de Mello Valeria Regina Zanetti ${ }^{2}$}

Resumo: Este trabalho tem a finalidade de apresentar uma breve análise a respeito de dois filmes lançados sobre a história do casal de gangsteres Bonnie Parker e Clyde Barrow.que atuaram na região do Texas, Estados Unidos durante a década de 1930, assim como suas diferenças e semelhanças com a história verdadeira do casal. O primeiro filme a ser analisado, "Bonnie e Clyde- Uma Rajada de Balas" (1967), e o segundo a minissérie para TV "Bonnie \& Clyde" (2013), apresentam a carreira, assim como a popularidade, do casal de formas diferentes, gerando questionamentos a respeito de sua veracidade histórica, tema abordado no presente artigo a partir de análises de críticas e biografias escritas sobre os mesmos.

Palavras-chave: História; Cinema; Violência; Década de 30.

\footnotetext{
${ }^{1}$ História/Universidade do Vale do Paraíba-Univap, Brasil. E-mail: tlrbm@hotmail.com.

2 História/Universidade do Vale do Paraíba-Univap, Brasil. E-mail: vzanetti@univap.br.
} 